\title{
SEO no jornalismo digital: uma análise sobre a visibilidade noticiosa da vitória de Jair Bolsonaro nas eleições presidenciais de 2018
}

\author{
SEO in digital journalism: \\ an analysis on the news visibility of Jair Bolsonaro's victory in the \\ presidential elections of 2018 \\ EI SEO en el periodismo digital: \\ un análisis sobre la visibilidad de noticias de la victoria de \\ Jair Bolsonaro en las elecciones presidenciales de 2018
}

\author{
Soraya Venegas Ferreira \\ Universidade Estácio de Sá - SP - Brasil \\ ORCID: https://orcid.org/0000-0002-0950-7188 \\ Endereço Currículo Plataforma Lattes: http://lattes.cnpq.br/8170179018935438 \\ E-mail: sosovenegas@yahoo.com.br \\ Erick Nunes da Costa \\ Universidade Estácio de Sá - SP - Brasil \\ ORCID: https://orcid.org/0000-0002-0860-3098 \\ Endereço Currículo Plataforma Lattes: http://lattes.cnpq.br/8155522368776267 \\ E-mail: nuneserick96@gmail.com
}

\begin{abstract}
Resumo: Qual a relação de $S E O$ e $S E R P$ com o Jornalismo? Para os que atuam no Jornalismo Digital, a aplicação das técnicas de Search Engine Optimization (SEO) pode fazer a diferença na visibilidade de uma matéria a partir de seu posicionamento na Search Engine Results Page (SERP) do Google. As técnicas de SEO ainda são pouco praticadas nos portais de notícias. Como listado em manuais, elas devem estar alinhadas ao conteúdo jornalístico de qualidade, de acordo com critérios de noticiabilidade e potencializado pelos recursos oferecidos na web. Para entender como essas ferramentas e o jornalismo se encontram, optou-se por estudar os resultados da busca Bolsonaro eleições 2018 e com base nas matérias e suas estratégias de SEO, identificar como os portais G1, Agência Brasil e UOL posicionaram o conteúdo jornalístico sobre a vitória de Bolsonaro.
\end{abstract}

Palavras-chave: Jornalismo Digital. Critérios de Noticiabilidade. Técnicas de SEO. Eleições de 2018. Jair Bolsonaro. 


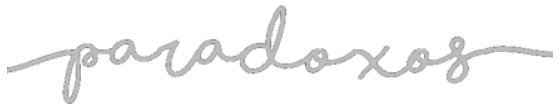

SEO no jornalismo digital: uma análise sobre

a visibilidade noticiosa da vitória de Jair Bolsonaro

nas eleições presidenciais de 2018

FERREIRA, COSTA, 2021

Abstract: What is the relationship between SEO, SERP and Journalism? For those who work in Digital Journalism, the application of Search Engine Optimization (SEO) techniques can make a difference in terms of the visibility of a story from its position on Google's Search Engine Results Page (SERP). SEO techniques are not widely practiced on major news portals. As listed in manuals, they must be aligned with quality journalistic content, according to the news criteria and enhanced by the resources offered by the web. To understand how these tools and journalism come together, we chose to study the results of the search Bolsonaro elections 2018 and through the analysis of the jornalistic articles and their SEO strategies, try to understand how the G1, Agência Brasil and UOL portals positioned their journalistic content on Bolsonaro's victory.

Keywords: Digital Journalism. News Criteria. SEO Techniques. 2018 elections. Jair Bolsonaro.

Resumen: ¿Qué tienen que ver las siglas SEO y SERP con el periodismo? Para aquellos que trabajan con periodismo digital, la aplicación de técnicas de optimización de motores de búsqueda (SEO) puede marcar la diferencia en términos de visibilidad de uma matéria periodística por su posición en la página de resultados de motores de búsqueda de Google (SERP). Las técnicas de SEO todavía se practican poco en los principales portales de noticias. Como enumerados en los manuales, ellas deben estar alineadas con contenidos periodísticos de calidad, de acuerdo con los criterios informativos y potenciados por los recursos que ofrece la web. Para entender cómo se unen estas herramientas y el periodismo, optamos por estudiar los resultados de la búsqueda de Bolsonaro elecciones 2018 y, a través del análisis de los artículos parodísticos y sus estrategias de SEO, comprender cómo los portales G1, Agência Brasil y UOL posicionaron su contenido periodístico acerca de la victoria de Bolsonaro.

Palabras clave: Periodismo digital. Criterios informativos. Técnicas SEO. Elecciones 2018. Jair Bolsonaro.

\section{SEO: Por que o Jornalismo precisa entender isso?}

Vitórias como a de Wilson Witzel para o governo do estado do Rio de Janeiro ou a de Jair Bolsonaro nas eleições presidenciais de 2018 surpreenderam muitos pesquisadores. Assim como já ocorrera nos Estados Unidos, os resultados de pleitos contemporâneos devem ser analisados segundo lógicas que superam "corpo a corpo das ruas" ou as notícias publicadas nos meios de comunicação de massa. O poder de convencimento das 


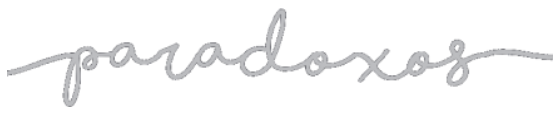

SEO no jornalismo digital: uma análise sobre

a visibilidade noticiosa da

vitória de Jair Bolsonaro

nas eleições presidenciais de 2018

FERREIRA, COSTA, 2021

publicações na Internet não é um fenômeno recente, mas assume diferentes contornos a cada novo algoritmo, aplicativo ou rede social digital lançados. É preciso contemplar o ambiente onde bots publicam e comentam e hashtags nem sempre corretamente grafadas nos confundem e colocam em xeque a credibilidade tanto de publicações "pessoais" como as atribuídas a sites jornalísticos. A cada segundo, milhões de consultas são feitas nos motores de busca, especialmente no Google, o mecanismo de pesquisa mais usado do mundo e, estar entre os primeiros do seu ranking de respostas é o desejo dos que almejam citações e visibilidade. Mas, para isso, é preciso usar técnicas, para além da "incontestável qualidade do conteúdo", para "convencer" os buscadores de que uma notícia merece estar nas primeiras posições da SERP (Search Engine Results Page).

Os que atuam no jornalismo digital precisam levar em conta particularidades que envolvem a classificação de notícias pelos motores de busca, que são sistemas formados por uma série de algoritmos que têm a função de rastrear e indexar os conteúdos da web para exibi-los de maneira ordenada nas pesquisas dos usuários. Os motores de busca funcionam, basicamente, em três etapas: Para começar, os robôs ou spiders rastreiam os conteúdos da web, seguindo os caminhos apontados pelos links, em busca de novas páginas e atualizações. Em seguida, as páginas rastreadas são indexadas por palavra-chave numa espécie de índice do buscador, como em uma biblioteca, mas a sua ordem no ranking muda a cada pesquisa. De acordo com a palavra-chave escolhida pelo usuário, o buscador vasculha o seu índice em busca das páginas que melhor atendam àqueles termos. É justamente nesse cenário que é importante que estudemos as técnicas de SEO (Search Engine Optimization).

O SEO é um sistema de classificação estudado na área de marketing, mas que, curiosamente, parece ser pouco explorado até mesmo pelos portais noticiosos mais tradicionais e de grande notoriedade. Esse artigo busca avaliar como as técnicas de $S E O$, bem como os critérios de noticiabilidade (TRAQUINA, 2008) foram usados nas notícias sobre a vitória de Jair Bolsonaro nas eleições presidenciais de 2018. Com base no estudo sobre como se dá a concorrência pelas primeiras posições nos resultados do buscador Google, pretendese identificar como a utilização eficiente das técnicas de $S E O$ pode levar um assunto e/ou um veículo às primeiras colocações na SERP. Na medida em que o jornalista adere a essas técnicas, aumenta a visibilidade do seu trabalho e do assunto por ele tratado. Para revelar 
como alguns portais utilizam, ou não, as técnicas de $S E O$, serão analisadas as notícias sobre a vitória de Bolsonaro em três portais distintos: G1; Agência Brasil e UOL.

\section{Tá no Google!: o Jornalismo Digital nas primeiras posições da SERP}

Pollyana Ferrari (2007) pontua que a Internet promoveu mudanças tanto no fazer jornalístico quanto no modo como o público se informa. Para Priscila Sarmento (2018), com a migração para as redes digitais, a responsabilidade dos jornalistas cresceu. Além de uma apuração criteriosa, de uma redação precisa e da incorporação adequada de elementos visuais (fotos e vídeos), torna-se relevante que o material veiculado atenda, não apenas aos tradicionais critérios de noticiabilidade, mas também aos quesitos dos mecanismos de busca, especialmente do Google. Expressões como "dar um Google" ou o verbo "googar", embora não oficialmente incorporados à língua portuguesa, são neologismos cotidianamente usados como sinônimos de pesquisar na Internet. E, se algo não é encontrado na SERP do Google, para o senso comum, ele simplesmente não existe.

Steven Levy (2012) conta que os fundadores do Google, Larry Page e Sergey Brin, criaram a empresa, em 1998, a partir do projeto BackRub, que buscava identificar quais links direcionavam uma determinada página. Larry e Brin pensaram em Googol - que representa o número $10^{100}$ - e que faria todo sentido para renomear o projeto. Como esse nome já estava em uso, Page não conseguiu registrar o domínio e acabou optando por Google para o nome do site. Para Alejandro Sánches-Ocaña (2013), o Google trata-se de um mecanismo de Inteligência Artificial (AI), pois além de armazenar os resultados das buscas, identifica o comportamento dos usuários, o que é demonstrado tanto pelos corretores ortográficos como pela identificação de sinônimos para as palavras digitadas. Para atingir a liderança, a ferramenta precisou superar falhas de computadores e erros de indexação e de rastreamento.

Maria Carolina Avis (2019) destaca que o Google ordena as notícias, com base na avaliação positiva dos usuários. Assim, os jornalistas são impelidos a produzir conteúdos que "agradem ao público", para que o portal onde eles são veiculados seja classificado como "relevante" para o Google, que acaba sendo um dos grandes responsáveis pela audiência. De acordo com Vinit Kumar Gunjan (2012), os usuários, raramente, 


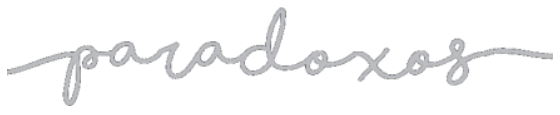

SEO no jornalismo digital: uma análise sobre

a visibilidade noticiosa da

vitória de Jair Bolsonaro

nas eleições presidenciais de 2018

FERREIRA, COSTA, 2021

ultrapassam a primeira página de resultados, ou seja, se o conteúdo jornalístico produzido estiver posicionado na segunda página em diante, a notícia será bem menos visualizada. Para superar essa condição, as matérias jornalísticas costumam usar links para estimular o internauta a permanecer mais tempo nos portais de notícias. Segundo Avis, quanto mais backlinks a notícia receber, mais relevante ela será.

Tomando-se como hipótese que o Google é a melhor ferramenta de busca do mundo (além de ser a mais utilizada) e que estar na primeira página da SERP leva ao aumento na audiência, é necessário conhecer técnicas para que sites e notícias específicas conquistem os primeiros lugares na SERP. Essa ajuda no posicionamento pode ser traduzida como "otimização de sites para mecanismo de busca", ou SEO. O próprio Google criou o manual Otimização de sites para Mecanismos de Pesquisa (SEO) - Guia do Google para Iniciantes para ensinar as principais técnicas para estar bem posicionado em sua SERP. Ao segui-las, é possível constatar sua eficiência também em outras ferramentas de busca, na medida em que parecem indicar boas práticas e melhores conteúdos na linguagem voltada para web.

O CEO do Google, Sundar Pichai ${ }^{1}$, ressalta a importância que a empresa atribui ao Jornalismo e, por isso, investiu em ferramentas e recursos específicos para área, que em conjunto formam a Iniciativa de Notícias, que se soma a outras que impactam diretamente o Jornalismo, tais como o Google Analytics; Google Adsense; Centro do publicador; The Fact Check Tools e Google Trends. Enquanto o Google Analytics trabalha em um sistema de AI para identificar os comportamentos do usuário e melhorar a experiência para ele, permitindo que o jornalista saiba quais foram as notícias mais acessadas, analisando sua audiência; o Google Adsense visa a monetizar sites de acordo com as visitas e cliques em anúncios.

Em 2019, o Google criou o novo Centro do publicador ${ }^{2}$ para os jornalistas. Segundo a empresa, a ferramenta ajuda os criadores de conteúdo a gerenciar a forma como a notícia é apresentada no Google News. O jornalista não precisa inserir o conteúdo no Centro do publicador para estar visível no Google Notícias, mas se o fizer, poderá personalizar as seções e o conteúdo da publicação; além de veicular anúncios na

\footnotetext{
${ }^{1}$ Iniciativa de Notícias Google. Sobre. Disponível em: https://newsinitiative.withgoogle.com/intl/pt_br/about/. Consultado em abril de 2020.

2 Centro do publicador. Ajuda. Disponível em: https://support.google.com/news/publishercenter/answer/9610084?hl=pt. Consultado em abril de 2020.
}

DOI: http://doi.org/10.14393/par-v6n1-2021-57127- Paradoxos, Uberlândia, v. 6, n. 1, p. 124-142, jan./jun. 2021| 128 


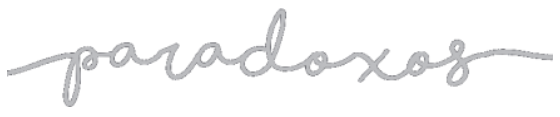

SEO no jornalismo digital: uma análise sobre

a visibilidade noticiosa da

vitória de Jair Bolsonaro

nas eleições presidenciais de 2018

FERREIRA, COSTA, 2021

área de conteúdo do Google News. The Fact Check Tools ${ }^{3}$ é a ferramenta do Google que visa expor o trabalho de jornalistas que se dedicam à checagem. Antes dela, o site de checagem precisava ser marcado com esquemas de dados estruturados ClaimReview, que permite que o Google reconheça o portal como um site de verificação de fatos. Com a nova ferramenta, o processo foi simplificado. Gorete Dinis, Carlos Costa e Osvaldo Pacheco destacam a importância do Google Trends, na medida em que "mostra o quão frequente um determinado termo de pesquisa é pesquisado pelos utilizadores em relação ao volume de pesquisas total" $(2015$, p.5). Segundo os autores, é possível coletar dados de 2004 até o presente, o que possibilita que jornalista analise a relevância de um determinado assunto com base no volume de busca.

\section{Para além dos critérios de noticiabilidade: Por uma outra "primeira página"}

Ter sua matéria estampada na primeira página de um jornal ou conquistar a capa de uma revista é um desejo tradicional dos jornalistas - iniciantes ou não. Para alcançar essa visibilidade, os critérios costumam ser dominados pelos que integram essa comunidade interpretativa, teorizada por Nelson Traquina (2008, 33-60) ao afirmar que o Jornalismo tem um "modo de ver, de falar e de agir". Mas, no Jornalismo Digital, os tradicionais critérios podem até levar uma matéria à homepage de um veículo, mas outros devem ser adicionados para que a tão sonhada visibilidade em rede seja alcançada.

Renan Vieira et. al. afirmou que "os valores-notícia são conceitos considerados como parte integrante da noção de noticiabilidade e, por conta disso, auxiliam a compreender os recursos que as empresas midiáticas e seus integrantes aplicam para organizar os assuntos considerados propensos a serem veiculados.” (2015, s/p). Mauro Wolf definiu valor-notícia como a resposta para a seguinte questão: "quais os acontecimentos que são considerados suficientemente interessantes, significativos e relevantes para serem transformados em notícia?” (2003, p. 195). Segundo o autor, os critérios devem ser aplicados rapidamente na decisão da seleção da notícia. Gislene Silva classificou esses critérios como:

\footnotetext{
${ }^{3}$ Ferramenta de verificação dos fatos. Sobre. Disponível em: https://toolbox.google.com/factcheck/about. Consultado em abril de 2020. 


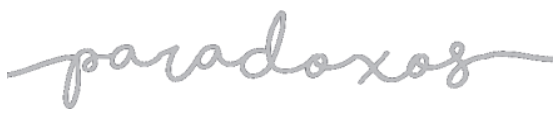

SEO no jornalismo digital: uma análise sobre

a visibilidade noticiosa da

vitória de Jair Bolsonaro

nas eleições presidenciais de 2018

FERREIRA, COSTA, 2021

(1) critérios de noticiabilidade na origem do fato (seleção primária dos fatos / valores-notícia), com abordagem sobre atributos como conflito, curiosidade, tragédia, proximidade etc; (2) critérios de noticiabilidade no tratamento dos fatos, centrados na seleção hierárquica dos fatos e na produção da notícia, desde condições organizacionais e materiais até cultura profissional; (3) critérios de noticiabilidade na visão dos fatos, sobre fundamentos ético-epistemológicos. (SILVA, 2014, p.51)

A autora complementa que existem valores-notícias que funcionam como "macrovalores-notícia ou pré-requisitos para qualquer seleção jornalística" (SILVA, 2014, p.63). Esses valores são classificados em 12 tipos e em uma rápida visada, percebe-se que a vitória de Bolsonaro atende a vários deles: impacto, proeminência (relacionada à notoriedade do personagem); conflito (polarização nas eleições); tragédia/drama; proximidade (eleições no Brasil); raridade (para muitos a vitória de Bolsonaro foi inusitada); surpresa (algo inesperado, surpreendente); governo (relacionado às eleições, pronunciamentos oficiais, entre outros); polêmica (ligada aos escândalos); justiça (relacionado às denúncias, investigaçõe e julgamentos); entretenimento/curiosidade e conhecimento/cultura. Esses valores, citados por Silva, sofrem alterações, conforme ela mesma indica, para "ganhar mais validade, testando sua operacionalidade no estudo dos acontecimentos selecionados" (SILVA, 2014, p.64).

Ivan Satuf (2014), em A rua manda notícias: dispositivos móveis e manifestações sociais na atualização dos critérios de noticiabilidade, analisou os critérios de noticiabilidade e valores-notícia tradicionais e acrescentou três específicos para os jornalistas digitais: hashtag, redundância e participação. A hashtag que tem a função de facilitar a busca e a agregação automática de conteúdo, o que ajuda o jornalista a apurar e a analisar o que está sendo mais discutido nas redes. A partir dos Trend Topics do Twitter, por exemplo, o jornalista consegue se guiar pelos assuntos mais tuitados e, a partir daí, propor sua pauta. A redundância, segundo o autor, aumenta a credibilidade da informação partilhada, na medida em que "um evento que possui vários ângulos feitos por muitas pessoas têm maior possibilidade de virar notícia” (SATUF, 2014, p. 327), ou seja, é um dos fatores que o jornalista digital precisa se atentar para que o veículo permaneça relevante para o público. A participação é demonstrada quando os jornalistas passam a ser cada vez mais pressionados a incorporar no noticiário conteúdos produzidos pelos cidadãos. Mas, a 


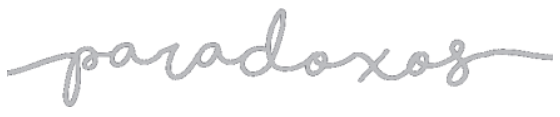

SEO no jornalismo digital: uma análise sobre

a visibilidade noticiosa da vitória de Jair Bolsonaro nas eleições presidenciais de 2018

FERREIRA, COSTA, 2021

adição dos critérios voltados especificamente para o jornalista digital ainda não são garantia de destaque na SERP. Para isso, é necessário retornar ao manual do Google.

As primeiras recomendações do guia são sobre o título da página ou publicação que deve ser coerente com o assunto que a página se define, evitando nomes genéricos. Sobre a definição da descrição da página, ela deve ser um breve resumo sobre o que a página trata. Sobre a estrutura dos links da página, que precisa ser renomeada de acordo com o conteúdo apresentado, aconselha-se evitar caracteres abstratos. O guia recomenda também que o desenvolvedor crie conteúdos com escrita de qualidade, isto é: evite duplicação de conteúdo e erros ortográficos; separe títulos e seções para a troca de assuntos; distribua links internos e externos na página e esses links precisam ser descritivos, evitando palavras vagas. O desenvolvedor deve ainda utilizar hierarquia de cabeçalho para as seções do texto da página, por exemplo, no título é preferível utilizar a tag $\langle h 1\rangle$, para o subtítulo: $\langle h 2\rangle$ e assim por diante, além de utilizar as palavras-chave corretas para melhor indexação da página.

O guia trata ainda da publicação correta das imagens, pois precisam ser renomeadas com as informações das fotos e vídeos. Além disso, elas precisam de atributos descritivos, chamados de atributo alt, para que a descrição possa ser mostrada, caso não apareça para o usuário do site. Um mecanismo que auxilia o site no desempenho e performance de SEO é o Ubersuggest, uma ferramenta de marketing digital, que possui diversas funcionalidades essenciais para que um site consiga um bom posicionamento no Google e que foi bastante útil para o entendimento sobre como os portais tiveram resultados diferentes ao noticiar a vitória de Jair Bolsonaro nas eleições de 2018.

\section{G1 e Bolsonaro: a conquista de visibilidade por caminhos distintos}

Com a utilização do Ubersuggest, foi realizada uma análise preliminar de SEO no portal de notícias G1. A ferramenta revela porque ele está, quase sempre, nas primeiras colocações nas pesquisas do Google em relação aos seus concorrentes diretos, ou seja, os outros sites de notícias, como Agência Brasil e UOL, que serão estudados no case Bolsonaro. Ao fazer uma consulta pelo G1 no Ubersuggest, a ferramenta entrega os seguintes resultados: 
Figura 1: Análise de $S E O$, do Ubersuggest, no portal do G1

Visăo Geral do Dominio: gl.globo.com

PALAVRAS-CHAVI
OROANICAS

4.353 .754
TRAIESOO ORGANICC 24.071 .635
PONTUACLAO DE DOMINIO O

90
BACKLINKS $O$

19.103.698

Com base nos dados é possivel constatar a grande visibilidade do portal do G1. Suas páginas mais visualizadas no momento da pesquisa eram: a previsão do tempo do Rio de Janeiro; a página principal; a previsão do tempo de São Paulo; o resultado da Mega-Sena; e o resultado da Quina. O G1 consegue esse desempenho tão positivo, porque o volume de pesquisas no Google com as palavras-chave relacionadas às páginas, citadas acima, está na casa dos milhões por mês e o $G 1$ está nas primeiras posições nessas pesquisas.

Como visto anteriormente, a grande quantidade de backlinks que um site possui é um dos itens mais importantes para o Google classificá-lo como relevante. Na figura, percebe-se que são quase 20 mil links do $G 1$ que estão presentes em outros sites. Na análise, o Ubersuggest revelou que foram quase 126 mil domínios diferentes que inseriram links apontando para o portal do G1. Numa escala de 0 a 100 usada pelo Google, o G1 alcança 90, o que demonstra sua grande visibilidade nas pesquisas. Contudo, ele não é o único site jornalístico com uma pontuação de domínio próxima de 100. O Estadão possui pontuação de domínio 89; a Folha de São Paulo, 92; o R7, 87; a Revista Veja, 90; e a Agência Brasil, 87. De modo geral, o G1 é superior aos outros quanto ao número de visitantes mensais e palavras-chave orgânicas, o que pode ser um indicador de resposta para o fato de o Gl ficar, quase sempre, à frente de seus concorrentes diretos na pesquisa orgânica do Google.

A partir da observação das estratégias de $S E O$ do $G 1$, buscou-se afunilar a pesquisa através do uso de palavras-chave que nos levariam a um intenso tráfego de informações, daí a escolha por bolsonaro eleições 2018. Segundo Priscilla Dibai (2018), Jair Messias Bolsonaro, nascido em Campinas, concluiu o curso de oficiais na Academia Militar de Agulhas Negras, em 1977 e formou-se em Educação Física pela Escola de 


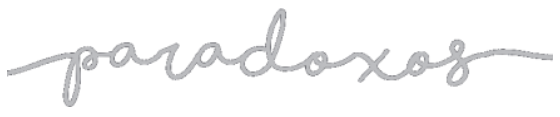

SEO no jornalismo digital: uma análise sobre

a visibilidade noticiosa da

vitória de Jair Bolsonaro

nas eleições presidenciais de 2018

FERREIRA, COSTA, 2021

Educação Física do Exército, em 1983. Em 1986, ao liderar protestos contra os salários baixos dos militares, chegou a ser preso. Dois anos depois, ingressou na reserva, como capitão, após ser eleito vereador no Rio de Janeiro. Foi deputado federal por sete mandatos entre 1991 e 2018. Tornou-se conhecido pela sua personalidade polêmica e truculenta e por posicionamentos populistas e declaradamente conservadores, explicitados em declarações classificadas como discurso de ódio, nas quais defendeu a tortura, posicionamentos homofóbicos e pró-armamentistas. Com esse currículo e muita visibilidade noticiosa, não parecia ser capaz de chegar à presidência.

No primeiro turno das eleições de 2018, Bolsonaro não era mais uma surpresa. De acordo com as estatísticas do Tribunal Superior Eleitoral (TSE), no primeiro turno, ele obteve $46 \%$ dos votos contra $29 \%$ do segundo colocado, Fernando Haddad. Com intensa campanha nas redes sociais e grupos de WhatsApp, além de evitar os debates televisivos, o candidato consolidou a vitória em 28 de outubro de 2018 , com 55,13\% dos votos válidos. Nessa eleição, de acordo com os dados do TSE, o índice de abstenção chegou a 22\%, ou seja, quase 30 milhões de pessoas. Segundo Cioccari e Persichetti (2018), as redes sociais de Bolsonaro são marcadas por palavreados denominados como discurso de ódio, que:

(...) ganha existência concreta e torna-se disponível àqueles a quem visa denegrir e também àqueles a quem intenciona incitar contra os denegridos. Concretizado, o discurso realiza seus efeitos nocivos, destacando: ataque à dignidade alheia e violações a direitos fundamentais. Em suma, manifestado publicamente, o discurso do ódio causa o dano. (...) Em suas redes sociais luta contra um perfil autoritário e punitivista que foi construído em paralelo à sua tentativa de provar o contrário. Entra em embates diretos com a grande imprensa que reverbera até mesmo seu silêncio. (...) Além disso, o debate político em campanhas eleitorais transborda nas redes sociais, palco de disputas ideológicas vazias de argumentação e de pouca consistência, onde sobram agressões, xingamentos e ódio. $\mathrm{O}$ ódio em Bolsonaro é repercutido intensamente pela mídia. Até mesmo o silêncio de Bolsonaro virou notícia. (CIOCCARI; PERSICHETTI, 2018, pp. 209; 212; 213)

Para essa análise do case Bolsonaro nas Eleições 2018, será utilizada, novamente, a ferramenta Ubersuggest. 
Figura 2: Link; pontuação do domínio; compartilhamento social; backlinks e visitas das páginas melhores ranqueadas pelo Google, através da palavra-chave: bolsonaro eleições 2018

\begin{tabular}{|c|c|c|c|c|c|}
\hline & SERP DO GOOGLE 2 & $\begin{array}{l}\text { HUSA } \\
\text { VISITAS }\end{array}$ & LIGAÇŌES & DS 2 & $\begin{array}{l}\text { COMP. } \\
\text { SOCIAIS }\end{array}$ \\
\hline 11 & ptwikipedia.org/wiki/Elei\%C3\%A7\% _. $\mathbf{Z}$ & 42. & 16 & 100 & 41. \\
\hline 2 & gl.globo.com/politica/eleicoes/201... $\mathbf{Z}$ & 22 & 108 & 90 & 46,316 \\
\hline 3 & gl.globo.com/politica/eleicoes/201... $\mathbf{L}$ & 13 & 268 & 90 & 118.853 \\
\hline 4 & agenciabrasil.ebc.com.br/politica/n... $\mathbf{L}$ & 9 & 49. & 87 & 87 \\
\hline 5 & politica.estadao.com.br/eleicoes/20... $\boldsymbol{L}$ & 6 & 19 & 89 & 3 \\
\hline 6 & veja.abril.com.br/politica/eleicoes-2.. $\mathbf{L}$ & 4 & 11 & 90 & 20.775 \\
\hline 7 & exame.abril.com.br/brasil/ao-vivo-b... $\mathbf{L}$ & 3 & 9 & 90 & 7.550 \\
\hline 8 & especiais.gazetadopovo.com.br/ele... $\mathbf{E}$ & 2 & 53 & 86 & 87 \\
\hline
\end{tabular}

Ao analisar o quadro à cima percebe-se que a pontuação máxima de domínio e a quantidade de visitas mensais prevaleceram diante dos outros critérios. Com isso, a página da Wikipédia conquistou a primeira posição na busca. Também percebe-se que não apenas na segunda, mas também na terceira posição da pesquisa está o portal G1, que tem sua visibilidade associada a uma reputação de credibilidade. O Guia de SEO do Google destaca que um conteúdo de qualidade é diferencial na conquista de audiência, nessa noção de "conteúdo de qualidade" estão inseridos os recursos da web, como entregar ao internauta a informação que ele busca, de maneira simples e cuja relevância seja clara a ponto de levar muitas pessoas a compartilhá-la. O G1 é um portal com milhões de notícias e, dentre elas, o Ubersuggest informou que, apenas, 246 páginas do $G 1$ possuem algum tipo de erro crítico. A maioria desses erros estão em descrições de páginas duplicadas e conteúdos com poucas palavras, ou seja, a exceção dessas 246 páginas, o $G 1$ consegue atender as recomendações do Google nas outras milhões de notícias. 


\section{O SEO nos portais de notícias e a vitória de Bolsonaro}

O jornalismo digital oferece diferenciais para internauta e, entre os principais, está a hipermídia, ou seja, uma única notícia é formada por texto; imagem; infográfico; link; áudio e vídeo. A inserção desses elementos impactam no $S E O$ e, potencializam destaque na SERP. Nesse contexto, serão analisadas três notícias em veículos diferentes: G1; Agência Brasil; e UOL. Elas tratam do fato de Jair Bolsonaro ter sido eleito presidente da República nas eleições de 2018. Há outros veículos noticiosos bem posicionados na pesquisa por palavras-chave, mas não através de notícia específica sobre a vitória. A página do Estadão $o^{4}$ está em segundo lugar como concorrente direto, mas em uma página com diversas notícias relacionadas à palavrachave escolhida para análise. A página da Revista $V e j a^{5}$, que está em sexto lugar, leva para uma página com uma série de notícias que contemplam a apuração das eleições. E a página da Gazeta do $P_{o v o}{ }^{6}$ é uma página exclusiva do veículo com informações diversas sobre o presidente Jair Bolsonaro. Em atendimento aos critérios anteriormente explicitados, optou-se pelas três notícias citadas anteriormente.

As matérias serão analisadas em ordem de posicionamento na pesquisa com a palavra-chave: bolsonaro eleições 2018. A primeira notícia e melhor ranqueada é a do G1, cujo título é: Jair Bolsonaro é eleito presidente e interrompe série de vitórias do $P T^{7}$. O título é sugestivo, pois demonstra que a notícia tratará da trajetória de uma vitória que mudaria os planos de governo de um partido que ocupava a presidência há 14 anos. No total, foram 47 links internos apontando para outras notícias do G1. Esses links foram bem distribuídos e inseridos de acordo com as recomendações do Google, ou seja, os links foram incluídos dentro de seus respectivos contextos e não em palavras soltas como, por exemplo, clique aqui. Ao utilizar o navegador Google Chrome e exibir o código fonte da página $(C t r l+u)$, percebe-se que outra técnica de

\footnotetext{
${ }^{4}$ Disponível em: https://politica.estadao.com.br/eleicoes/2018/candidatos/br/presidente/jair-bolsonaro, 17. Acesso em: 25 de ago. de 2020.

5 Disponível em: https://veja.abril.com.br/politica/eleicoes-2018-segundo-turno-apuracao-resultadopresidente-ao-vivo/. Acesso em: 25 de ago. de 2020.

6 Disponível em: https://especiais.gazetadopovo.com.br/eleicoes/2018/candidatos/presidente/jair-bolsonaro/. Acesso em 25 de ago. de 2020.

7 Disponível em: https://g1.globo.com/politica/eleicoes/2018/noticia/2018/10/28/jair-bolsonaro-e-eleitopresidente-e-interrompe-serie-de-vitorias-do-pt.ghtml. Acesso em: 25 de ago. de 2020.

DOI: http://doi.org/10.14393/par-v6n1-2021-57127-Paradoxos, Uberlândia, v. 6, n. 1, p. 124-142, jan./jun. 2021| 135
} 
SEO foi bem utilizada na notícia: o uso correto da hierarquia de cabeçalho, ou seja, o único item com a tag $\langle h l>$ é o título, como na imagem à seguir:

Figura 3: Código fonte da notícia Jair Bolsonaro é eleito presidente e interrompe série de vitórias do $P T$, parte $\langle h l>$

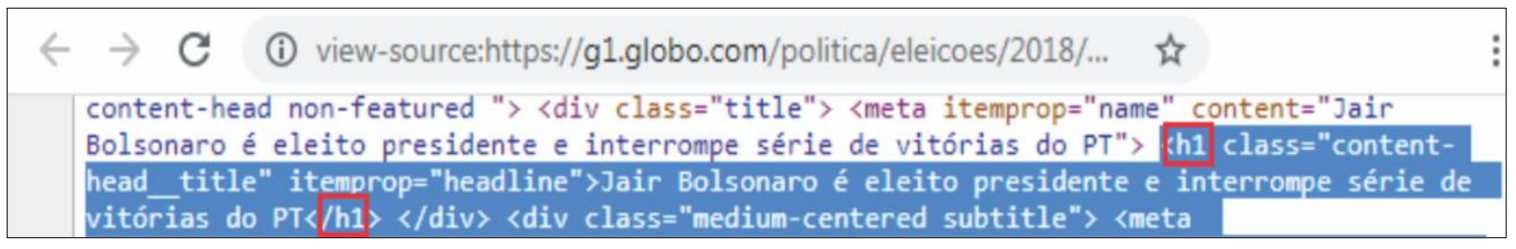

Além disso, o subtítulo e todos os intertítulos da notícia estão escritos com a tag $<h 2>$, o que está correto para o $S E O$, conforme a imagem abaixo revela:

Figura 4: Código fonte da notícia Jair Bolsonaro é eleito presidente e interrompe série de vitórias do $P T$, parte $\langle\mathrm{h} 2>$

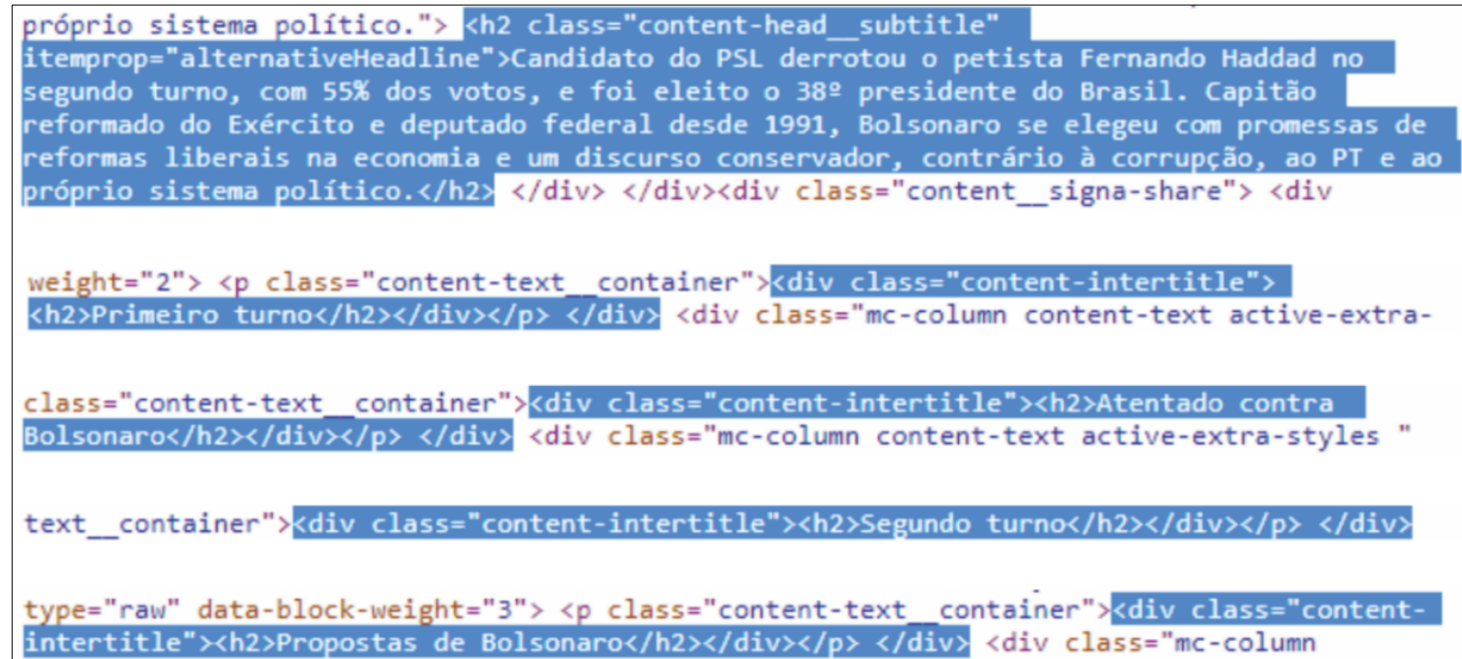

Outro ponto positivo de $S E O$ que o Gl utiliza na notícia, com êxito, é o atributo alt em todas as mídias inseridas. Essa notícia contém uma imagem, com créditos do Estadão; e três vídeos da própria Globo: o primeiro e o segundo do Jornal Nacional; e o terceiro do Jornal das Dez. O que contou ponto de SEO com esses vídeos é o fato de que eles foram incorporados na própria página do $G 1$ e não por um link de outra plataforma como, por exemplo, o YouTube. A notícia contém, aproximadamente, 1800 palavras. A notícia do G1 está em segundo lugar na pesquisa 
SEO no jornalismo digital: uma análise sobre

a visibilidade noticiosa da vitória de Jair Bolsonaro nas eleições presidenciais de 2018

FERREIRA, COSTA, 2021

orgânica do Google, atrás apenas da Wikipédia. Ou seja, é o veículo noticioso melhor posicionado na busca por conta dos critérios explícitos na imagem a seguir:

Figura 5: Critérios de avaliação do Google para ranquear a notícia do G1 em primeiro lugar entre os veículos noticiosos

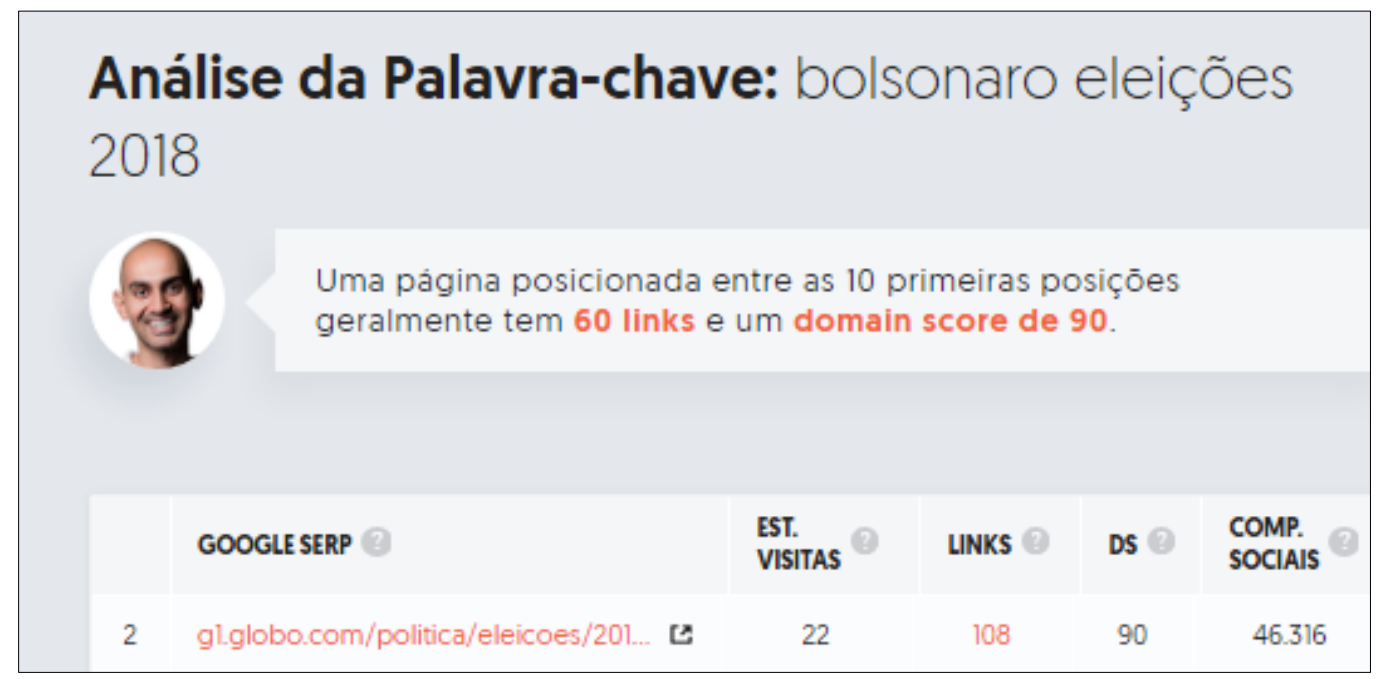

A segunda notícia que será analisada é a da Agência Brasil, cujo título é: Com $100 \%$ das urnas apuradas, Bolsonaro obteve 57,7 milhões de votos ${ }^{8}$. Essa notícia é mais curta, em relação a do G1. Ela possui, aproximadamente, 260 palavras. Ao analisar o $S E O$, percebe-se um erro que a fez perder pontos, segundo as recomendações do Google. Esse erro é o não respeito à hierarquia das tags de cabeçalho. O título da notícia foi inserido com a tag $\langle h 2\rangle$, conforme revela a imagem a seguir:

Figura 6: Código fonte da notícia Com 100\% das urnas apuradas, Bolsonaro obteve 57,7 milhões de votos, parte do erro título em $\langle h 2>$

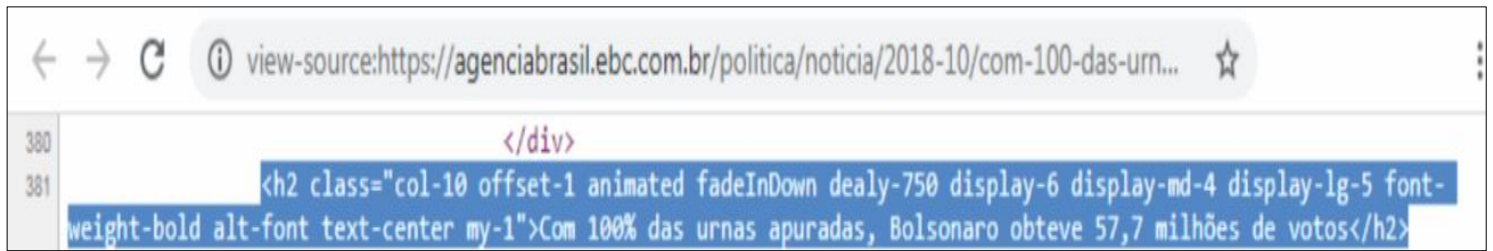

${ }^{8}$ Disponível em: https://agenciabrasil.ebc.com.br/politica/noticia/2018-10/com-100-das-urnas-apuradasbolsonaro-teve-577-milhoes-de-votos. Acesso em: 25 de ago. de 2020.

DOI: http://doi.org/10.14393/par-v6n1-2021-57127-Paradoxos, Uberlândia, v. 6, n. 1, p. 124-142, jan./jun. 2021| 137 


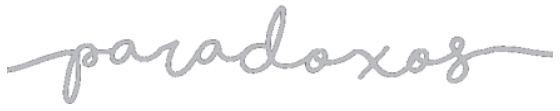

SEO no jornalismo digital: uma análise sobre

a visibilidade noticiosa da vitória de Jair Bolsonaro nas eleições presidenciais de 2018

FERREIRA, COSTA, 2021

Em contrapartida, a tag $<h 2>$ foi utilizada corretamente no intertítulo. Além disso, as imagens da notícia contém o atributo alt inserido de maneira correta, o que soma positivamente quanto ao SEO. Essa notícia da Agência Brasil contém dois deslizes gramaticais. O primeiro está em “(...) Com esses resultado (...)” e a segunda está na legenda da segunda imagem: “(...) Jair Bolsonaro votou no Rio de Janeiro neste segundo tunro (...)". (grifo nosso). Porém, os erros gramaticais contam poucos pontos negativos para o SEO da notícia. O que está em destaque para seu ranqueamento em quinto lugar na pesquisa com a palavra-chave bolsonaro eleições 2018 foi a quantidade de backlinks que, no total, foram 49 e as visitais mensais que, em até 2020, mantem-se com média 6 visitas mensais.

A terceira e última notícia analisada é a do portal $U O L$ com o título: $U m$ capitão no Planalto ${ }^{9}$. Esse título, com informações insuficientes e sem verbo, foi complementado com o subtítulo: Embalado por antipetismo, Jair Bolsonaro chega à Presidência com missão de "dar um jeito no país". Essa notícia foi um especial do $U O L$ com mais de 5 mil palavras. No ponto de vista do $S E O$, a quantidade de palavras, de links, fotografias e vídeos seria fator determinante para um bom ranqueamento, pois, de acordo com as recomendações do Google, seria elencado como conteúdo de qualidade. No total, a notícia do UOL contém 34 links externos: alguns para o domínio da Folha de São Paulo e outros para o Uol Notícias. Essa notícia apresenta nove imagens com o atributo alt usado corretamente. Além disso, oferece um carrossel com 51 fotografias comentadas com o título: Conheça a trajetória de Jair Bolsonaro. Os dois vídeos, assim como no G1, foram inseridos no próprio site do $U O L$, sem a necessidade de links de terceiros. A imagem a seguir revela uma curiosidade dessa notícia do $U O L$ no ranqueamento orgânico com a palavra-chave bolsonaro eleições 2018:

${ }_{9}^{9}$ Disponível em: https://www.uol/eleicoes/especiais/jair-bolsonaro-eleito-presidente-eleicoes-2018.htm. Acesso em: 25 de ago. de 2020.

DOI: http://doi.org/10.14393/par-v6n1-2021-57127-Paradoxos, Uberlândia, v. 6, n. 1, p. 124-142, jan./jun. 2021| 138 


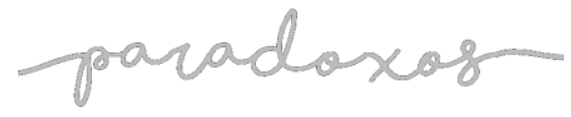

SEO no jornalismo digital: uma análise sobre

a visibilidade noticiosa da

vitória de Jair Bolsonaro

nas eleições presidenciais de 2018

FERREIRA, COSTA, 2021

Figura 7: Critérios de avaliação do Google para ranquear a notícia do $U O L$ na $11^{\text {a }}$ colocação

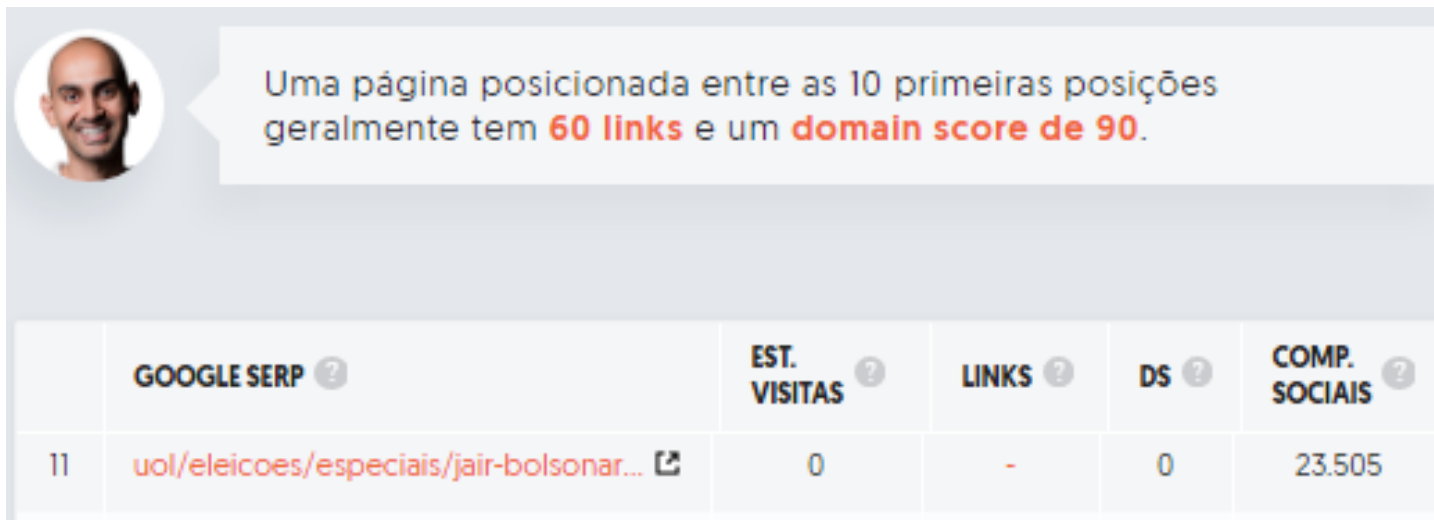

O curioso ao analisar os dados acima é que, segundo Neil Patel, no Ubersuggest, para estar entre as dez primeiras colocações, uma página deve ter 60 backlinks e pontuação de domínio de 90 . O que se percebe é que a notícia do $U O L$ ficou uma posição abaixo da décima e não contém nem backlink nem pontuação de domínio. A pontuação de domínio 0 é por conta de ser uma página única e específica do $U O L$ com domínio separado do UOL Notícias. Em contrapartida, a notícia possui um número considerável de compartilhamentos. Dessa forma, é possível concluir que o que prevaleceu nesse ranqueamento foi o conteúdo de qualidade, segundo os critérios puramente jornalísticos, que fez com que mais de 23 mil pessoas compartilhassem, expontaneamente, a notícia. Assim, a notícia do $U O L$ superou muitos outros veículos noticiosos com alta pontuação de domínio, como revela a imagem a seguir:

Figura 8: Notícia do $U O L$, mesmo sem pontuação de domínio, supera outras páginas no ranking

\begin{tabular}{|c|c|c|c|c|c|}
\hline & GOOGLE SERP & $\begin{array}{l}\text { EST. } \\
\text { VISITAS }\end{array}$ & LINKS & DS (2) & $\begin{array}{l}\text { COMP. } \\
\text { SOCIAIS }\end{array}$ \\
\hline 11 & uol/eleicoes/especiais/jair-bolsonar... $\mathbf{E}$ & 0 & - & 0 & 23.505 \\
\hline 12 & bbc.com/portuguese/brasil-457680... [ & 0 & - & 93 & 6.134 \\
\hline 13 & bbc.com/portuguese/brasil-457666... [ & 0 & - & 93 & 7.247 \\
\hline 14 & em.com.br/app/noticia/politica/20.. ¿ & 0 & - & 86 & 0 \\
\hline 15 & brasildefato.com.br/2018/10/29/58-... L & 0 & - & 70 & 0 \\
\hline
\end{tabular}




\section{Considerações finais}

Apesar de pouco conhecidas pelos jornalistas e ainda rudimentarmente empregadas por alguns sites, é possivel reconhecer a importância do SEO para o jornalismo digital. Como o Google é, na maioria das vezes, a porta de entrada para os visitantes dos sites, seus critérios precisam ser dominados por aqueles que almejam uma boa colocação na SERP. Esse é justamente o caso do $G 1 \mathrm{com}$, em média, 24 milhões de acessos mensais. Em contrapartida, apenas seguir à risca as orientações do manual do Google, como faz o $G 1$ em suas notícias, não é garantia de sucesso, mas ajuda e muito. Nas notícias observadas nesse estudo, foram constatados problemas no $S E O$, a exceção da do $G 1$ e do $U O L$. Outras estratégias a serem destacadas dizem respeito a qualidade do conteúdo digital, em termos de quantidade de informação, hipermídia e diversidade de backlinks.

Não se pode esquecer dos tradicionais critérios de noticiabilidade, da redação e produção para web e do embasamento das técnicas jornalísticas para criação de um conteúdo de qualidade para conquistar um bom posicionamento na SERP. Dentre as três notícias analisadas, a página especial do $U O L$ se destacou por não possuir tráfego mensal, nem pontuação de domínio, nem backlinks. Sua boa colocação pode ser atribuida a critérios fundamentalmente jornalísticos: conteúdo extenso e aprofundado, superior ao dos concorrentes e com recursos multimídia, sem deixar de lado as recomendações do Google. Dessa forma, a matéria do $U O L$ chegou a superar veículos com visitas mensais, backlinks e pontuação de domínio. Observou-se que a matéria do $U O L$ foi a mais completa e com mais detalhes sobre o tema, mas não conquistou as primeiras posições por conta de fatores externos, que são determinantes para o ranqueamento.

A opção pelas palavras-chave bolsonaro eleições 2018 se mostrou adequada e suficiente para análise, sem que se pretendesse fazer quaisquer juizos de valor sobre a personalidade do presidente, nem suas convicções ou discutíveis estratégias de campanha, mas, apenas, selecionar um assunto que atendesse a diversos critérios de noticiabilidade. Ao efetuar a busca, observou-se que muitos veículos noticiosos publicaram sobre tema. Poderia ter sido feita uma consulta manual no Google para analisar a SERP, porém, como 


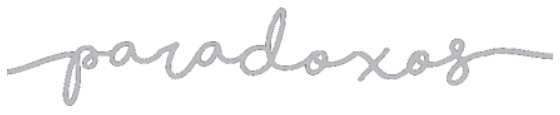

SEO no jornalismo digital: uma análise sobre

a visibilidade noticiosa da vitória de Jair Bolsonaro nas eleições presidenciais de 2018

FERREIRA, COSTA, 2021

o buscador mostra resultados, dependendo do caso, de acordo com os interesses do usuário, optou-se pelo Ubersuggest, criado, exclusivamente, para que fosse possível realizar uma consulta livre de caches e isenta de interesses pessoais. A ferramenta também revelou os critérios usados pelo Google para levar as notícias às primeiras posições, porém não foi possivel determinar o peso que o buscador atribui, especificamente, a cada critério ao combiná-los no processo de ranqueamento.

\section{Referências bibliográficas}

ALVAREZ, Barbara Zamberlan. Cartilha de recomendações de SEO para jornalistas online. Pontifícia Universidade Católica do Rio Grande do Sul. 2011.

AVIS, Maria Carolina. SEO de verdade: se não está no Google, não existe. Editora InterSaberes, 2019.

Centro do publicador. Ajuda. Disponível em:

https://support.google.com/news/publisher-center/answer/9610084?hl=pt. Consultado em abril de 2020.

CIOCCARI, Deysi; PERSICHETTI, Simonetta. Armas, ódio, medo e espetáculo em Jair Bolsonaro. In: Revista Alterjor, versão 18, vol. 2, p. 201-214, 2018.

DIBAI, Priscilla Cabral. A direita radical no Brasil pós-redemocratização: o caso de Jair Bolsonaro. Salvador - BA, 2018.

Ferramenta de verificação dos fatos. Sobre. Disponível em:

https://toolbox.google.com/factcheck/about. Consultado em abril de 2020.

FERRARI, Pollyana. Jornalismo digital. Editora Contexto, 2007.

GUNJAN, Vinit Kumar et al. Search engine optimization with Google. International Journal of Computer Science Issues, vol. 9, Issue 1, no 3, p. 206-214, 2012.

Iniciativa de Notícias Google. Sobre. Disponível em:

https://newsinitiative.withgoogle.com/intl/pt_br/about/. Consultado em abril de 2020.

LEVY, Steven. Google A Biografia: Como o Google pensa, trabalha e molda nossa vida. São Paulo. Universo dos Livros Editora, 2012.

SÁNCHEZ-OCAÑA, Alejandro Suárez. A verdade por trás do Google. Editora Planeta do Brasil, 2013. 


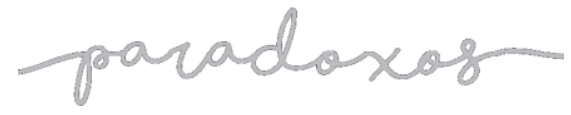

SEO no jornalismo digital: uma análise sobre

a visibilidade noticiosa da vitória de Jair Bolsonaro nas eleições presidenciais de 2018

FERREIRA, COSTA, 2021

SILVA, Gislene. Para pensar critérios de noticiabilidade. p. 51-69. In: Critérios de noticiabilidade: problemas conceituais e aplicações. Editora Insular, Florianópolis, 2014.

SARMENTO, Priscila Bueker. A inversão dos valores na mídia e sua influência na conduta jornalística. e-Com, v. 10, n. 2, p. 6-15, 2018.

SATUF, Ivan. A rua manda notícias: dispositivos móveis e manifestações sociais na atualização dos critérios de noticiabilidade. Liinc em Revista, Rio de Janeiro, v.10, n.1, p.317- 329, 2014. DOI: https://doi.org/10.18617/liinc.v10i1.671.

TRAQUINA, Nelson. Teorias do Jornalismo, Volume II: A tribo jornalística - uma comunidade interpretativa transnacional, 2. ed. Florianópolis: Insular, 2008.

VIEIRA, Renan Milanez; et. al. O acontecimento, o Newsmaking e as relações de concorrência entre os meios de comunicação. In: Intercom. XX Congresso de Ciências da Comunicação na Região Sudeste - Uberlândia - MG, 2015.

WOLF, Mauro. Teorias da comunicação. Lisboa: Editorial Presença, 2003 